\title{
Characterization of polydimethylsiloxane rubber upon photochemical, thermal, salt-fog ageings and exposure to acid vapours
}

\author{
F. Delor-Jestin ${ }^{1 *}$, N. S. Tomer ${ }^{1}$, R.P. Singh ${ }^{2}$ and J. Lacoste ${ }^{1}$ \\ ${ }^{1}$ Ecole Nationale Supérieure de Chimie de Clermont-Ferrand \\ Laboratoire de Photochimie Moléculaire et Macromoléculaire - UMR CNRS 6505 - \\ Ensemble Universitaire des Cézeaux - 63177 Aubière Cedex - France; \\ florence.jestin@univ-bpclermont.fr \\ 2 National Chemical Laboratory - Polymer Chemistry Division - Dr. Homi Bhabba \\ Road, Pune - 411 008- India
}

(Received: 2 November, 2005; Published: 8 May, 2006)

\begin{abstract}
The changes in the chemical structure and the physical properties of a filled crosslinked polydimethylsiloxane rubber were monitored as a function of various ageing factors. The variables included photochemical, thermal, salt-fog ageings and exposure to acid vapours. Unaged and aged samples were studied by IR spectroscopy, hardness measurements, Differential Scanning Calorimetry (DSC) and thermogravimetric analysis (TGA) coupled with IR spectroscopy. No significant oxidation was detected after all ageings, except for nitric acid treatment. The presence of aluminium trihydrate was clearly identified as responsible for the observed chemical changes. Then an important vulnerability of this filled silicone rubber towards the cross-linking reactions provoked by usual ageings was also detected. The DSC-thermoporosimetry measurements of the mesh size distribution gave a comparison of cross-linking densities for each ageing. The complementary analysis with TGAIR allowed us to differenciate the thermal stability of the formulation after various ageings and to acquire new knowledge about thermal decomposition.
\end{abstract}

\section{Introduction}

Polysiloxanes are widely used as protective surface coatings for a variety of specialized applications. The long term behaviour of cross-linked polysiloxanes is often very satisfactory. Compared with usual dienic elastomers, silicone rubber has outstanding heat resistance and a low chemical reactivity. However, it is important to recognise and identify the principal factors involved in rubber ageing so that degradation prevention can be applied. Knowledge of the amount of change that can be tolerated over the life of a material helps towards the determination of the lifetime expectancy.

Literature about polydimethylsiloxane (PDMS) ageing essentially concerns the unfilled uncross-linked polymer. The photochemical behaviour of polydimethyl siloxane (PDMS) oil has been examined previously [1-4]. Y. Israeli et al. have focussed in particular on the photoreactivity of the main substituent groups used in the silicone field. The other studies deal with the thermal behaviour of polysiloxanes. $\mathrm{N}$. Grassie et al. have reported on the thermal stability of PDMS to $300^{\circ} \mathrm{C}$ under vacuum [5]. Thermal degradation of PDMS has also been studied by G. Camino et 
al.[6,7]. Thermal oxidative degradation in the presence of air gives results much different from the decomposition in nitrogen. Kinetic treatment shows that PDMS thermal volatilization as rate of heating increases becomes dominated by rate of diffusion and evaporation of oligomers produced on its decomposition [6]. The products of the thermal degradation are essentially determined by the temperature and the heating rate [7]. The evaluation of cross-linking after photo-ageing of silicone rubber has been proposed by using calorimetrical analysis (Differential Scanning Calorimetry-DSC) and densimetry. No significant oxidation was detected, but competitive routes such as cross-linking and chain scission were clearly identified [8]. Most studies on filled cross-linked silicone rubber gave results on hydrophobicity changes after corona discharge and plasma treatment [9-13]. One of the major drawbacks with siloxanes is hydrolysis, which leads to low molecular weight cyclic fragments in the rubber network for which a mechanism has been proposed by $\mathrm{M}$. Zeldin et al. [9]. The hydrophobic character or the water repellancy of PDMS is due to the close packing of the methyl groups, which under usual conditions point outward from the surface. Reorientation of the main chain, a change in the surface roughness, the deposition of contaminants on the surface, or surface oxidation can play a major role in the change from a hydrophobic to a hydrophilic state on PDMS surface [10]. Owen et al. have summarized the plausible mechanisms for hydrophobicity recovery after exposure to corona or plasma [13]. Migration of low molar mass species is undoubtedly the process that most researchers in the field believe as the dominant mechanism for hydrophobicity recovery. Outdoor expositions of silicone rubber have also been carried out and analysed by X-ray photoelectron spectroscopy (XPS) to understand the water repellency [14-16]. Another paper is a review about the recent performance experience of silicone composite insulators in outdoor service [17]. The ageing of silicone started with the loss of hydrophobicity, and then a depolymerisation was also reported using gas chromatography-mass spectrometry [18]. The degradation is indicated by permanent changes such as increase in depolymerisation and changes in the surface physical structure brought about by an increase in the degree of crystallization of the polymer and the conglomeration of small particles into larger ones. Recent papers concerned the effect of antioxidants on the surface oxidation of cross-linked PDMS after air-plasma treatment [19]. Degradation at $180-200^{\circ} \mathrm{C}$ in air of PDMS rubber was studied by chemiluminescence [20]. Ageing is due to small fragments and catalyst solvents rather than the main siloxane network. Storage of siloxane rubbers in a closed inert atmosphere results in softening of the material. Thermal ageing studies on room-temperature rubbers and compression set experiments were also proposed to give the lifetime prediction [21]. Kinetics of the thermal degradation and thermal stability of conductive silicone rubber (unfilled, filled with carbon black or silica) have been studied by J. Zhang et al. [22]. The thermal stability of carbon black rubber was the best, compared to unfilled or silica elastomer.

We focussed our study on filled cross-linked PDMS and used different analytical technics such as IR spectroscopy, hardness measurements, DSC to evaluate the polymer long term behaviour upon usual ageings and specific acidic treatments. The new DSC-thermoporosimetry technique was first used upon photoageing of PDMS [8]. In this work we present new DSC-thermoporosimetry results for the estimation of the cross-linking level after various ageings. We will compare the competitive ways of degradation such as oxidation, post cross-linking and chain scission for each ageing. 


\section{Results and discussion}

\section{Study with FTIR spectroscopy}

First we analyzed the ATR-IR spectrum of the unaged cross-linked filled polydimethylsiloxane (Table 1, Figure 1) [27]. The specific bands attributed to PDMS are localised at 2960, 1256, 1090, 1030 and $795 \mathrm{~cm}^{-1}$. The main bands of the flame retardant are found at $3615,3524,3430$ and $3375 \mathrm{~cm}^{-1}$ due to hydroxyl bonds. The presence of silica is not significative for this analysis; the Si-O band from inorganic filler will be overlayed with the Si-O band of PDMS. The presence of the crosslinks due to peroxide is not detected because of the small quantity of curing agent. The other spectra (Figure 1) were obtained after UV irradiation, thermal exposure, salt-fog test, nitric acid treatment and sulphuric acid treatment. The spectra obtained by photochemical, thermal, salt-fog or sulphuric acid ageings were identical with the initial spectrum of unaged material, for various times of exposure. These results confirmed the silicone stability towards oxidation. The evolution of any oxidation products (carbonyl and hydroxyl) was not significant, even after 10.000 hours of accelerated photo-ageing or thermal exposure. The repeted cycle in salt-fog test was not a degradative test for the silicone material. The polymer was not damaged by sulphuric acid vapour even after two weeks of exposure. On the other hand the exposure under nitric acid vapours was very aggressive for silicone rubber. The quick formation of three bands in the region $1700-1300 \mathrm{~cm}^{-1}$ was observed after a few hours of this acid ageing. These bands are the nitrate bands, resulting from the decomposition of $\mathrm{Al}(\mathrm{OH})_{3}$. The intensity of the hydroxyl vibration $\left(3600-3400 \mathrm{~cm}^{-1}\right)$ is decreasing after 24 or 64 hours under acid exposure.

Tab. 1. Main absorption observed for unaged filled uncross-linked PDMS then assignments of IR bands ( $v=$ stretching vibration; $\delta=$ in-plane deformation).

\begin{tabular}{|l|l|}
\hline Wavenumber $\mathbf{( c m}^{-\mathbf{1}}$ ) & Tentative assignment \\
\hline $3615,3524,3432,3375$ & $v \mathrm{OH}$ of $\mathrm{Al}(\mathrm{OH})_{3}$ \\
\hline 2960 (median intensity) & $v \mathrm{CH}$ in $\mathrm{CH}_{3}$ \\
\hline 1646 (weak) & $v \mathrm{C}=\mathrm{C}$ \\
\hline 1408 (weak) & Not assigned \\
\hline 1256 (strong) & $v \mathrm{CH}$ in $\mathrm{Si}-\mathrm{CH} 3$ \\
\hline 1090 (strong) & $\mathrm{Si}-\mathrm{O}-\mathrm{Si}$ \\
\hline 1030 (strong) & $\mathrm{Si}-\mathrm{O}-\mathrm{Si}$ \\
\hline 795 (strong) & $\mathrm{Si}-\mathrm{O}-\mathrm{C}$ \\
\hline 730 (weak) & Not assigned \\
\hline 665 (weak) & Not assigned \\
\hline
\end{tabular}




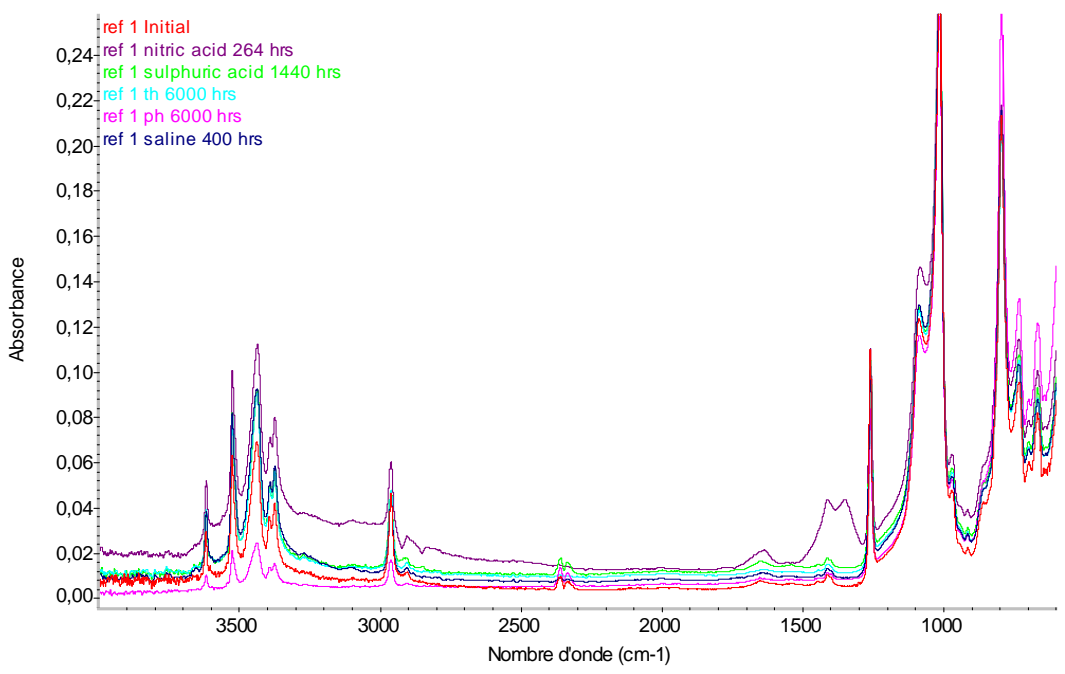

Fig. 1. FTIR-ATR spectra of silicone rubber before and after ageing.

Curve $a-$ Unaged sample; $b-6000$ hours after photochemical ageing; $c-6000$ hours after thermal ageing; $d-400$ hours after salt-fog test; e - 264 hours under nitric acid vapours; $f-1400$ hours under sulphuric acid vapours.

We also studied the crude PDMS (unfilled uncross-linked silicone, reference 870) and showed that no oxidation is detected after photochemical, thermal, sulfuric acid or nitric acid treatment (Figure 2). This proves that the silicone matrix is not affected by acid vapours in the absence of additives and fillers. The direct acidic treatment on aluminium trihydrate powder confirmed the results on filled polysiloxane (Figure 3). The formation of aluminium nitrate is clearly detected in this case.

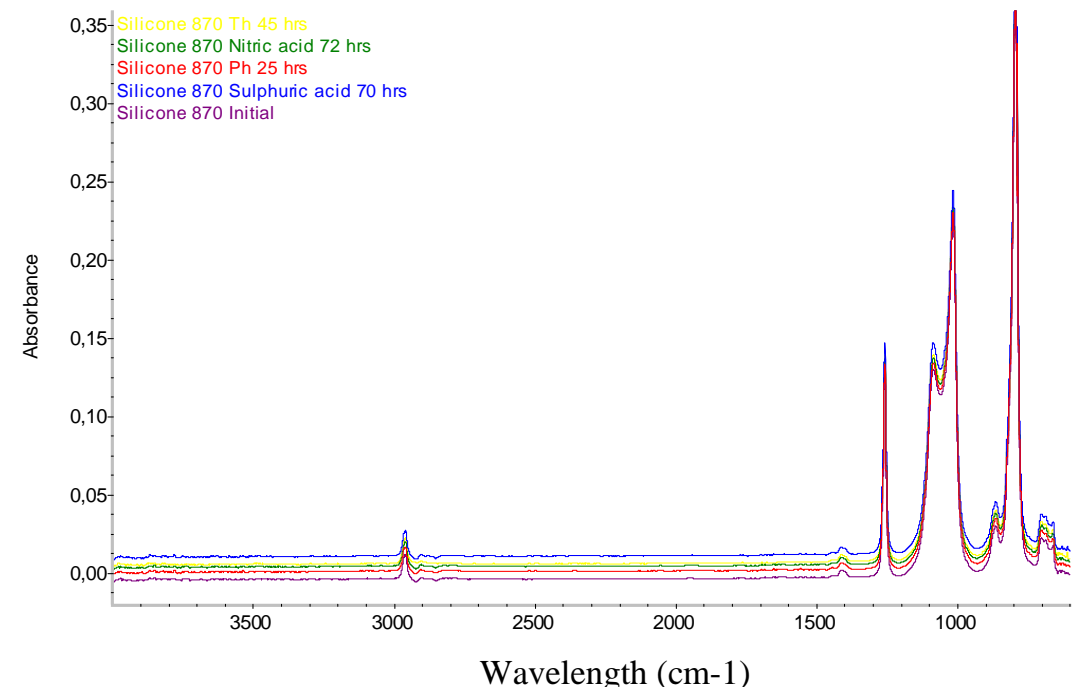

Fig.2. FTIR-ATR spectra of crude polysiloxane before and after ageing. 


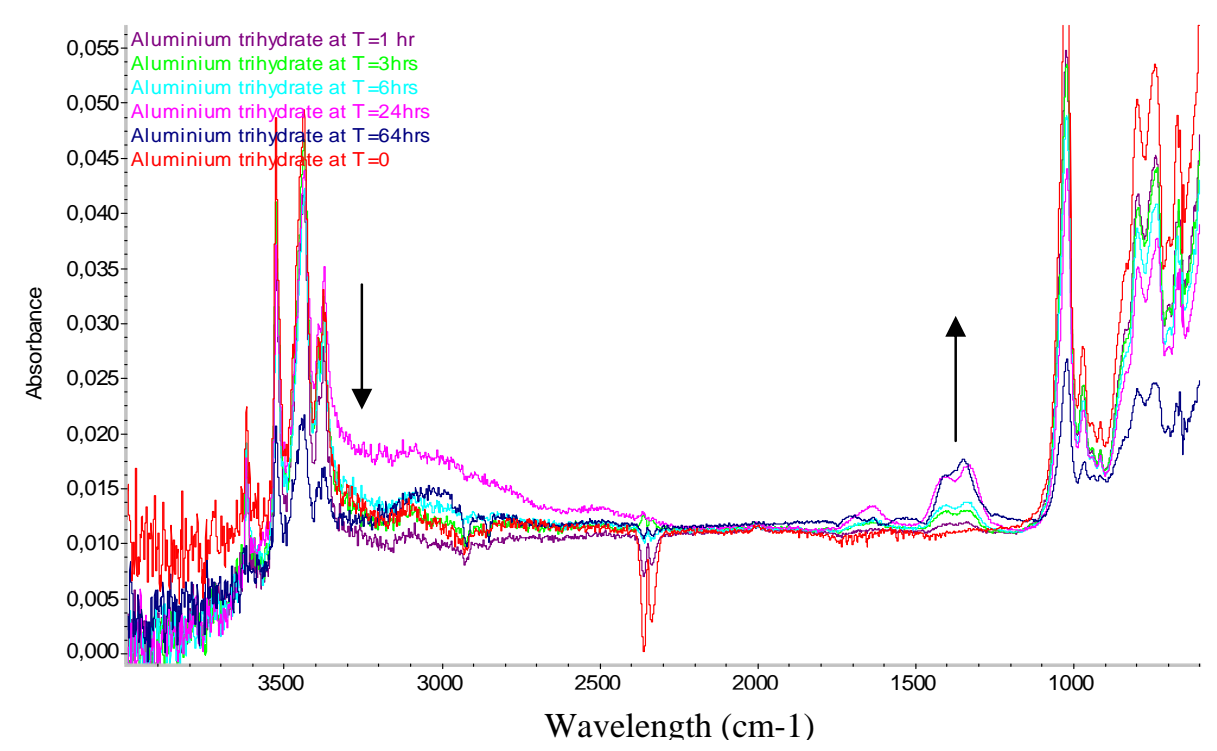

Fig. 3. Nitric acid treatment on aluminium trihydrate powder characterized by FTIR spectroscopy.

\section{Hardness measurements}

The hardness measurements are given in Figure 4. Hardness measurements on the initial material gave an average value of $70.0(+/-2.1)$ Shore A. During ageings the samples became harder on their surface layers. The surface is harder because the polymer chains cannot explore different configurations during constraint and are less flexible; hence the material is more cross-linked. The hardness values quickly increased after acidic treatments without induction period. After photo- or thermoageing an induction period of around 500 hours was detected, then the hardness increased till a stabilized value $87.1(+/-1.4)$ Shore A. The evolution towards hardness is accelerated after polluted ageings with acidic vapours. The evolution of the fire retardant with $\mathrm{HNO}_{3}$ is supposed to enhance the hardness of the rubber. The evolution with $\mathrm{H}_{2} \mathrm{SO}_{4}$ is more surprising because we could not detect any change on IR spectra. The results also show that post cross-linking reactions occur upon usual ageings such as UV and thermal exposures.

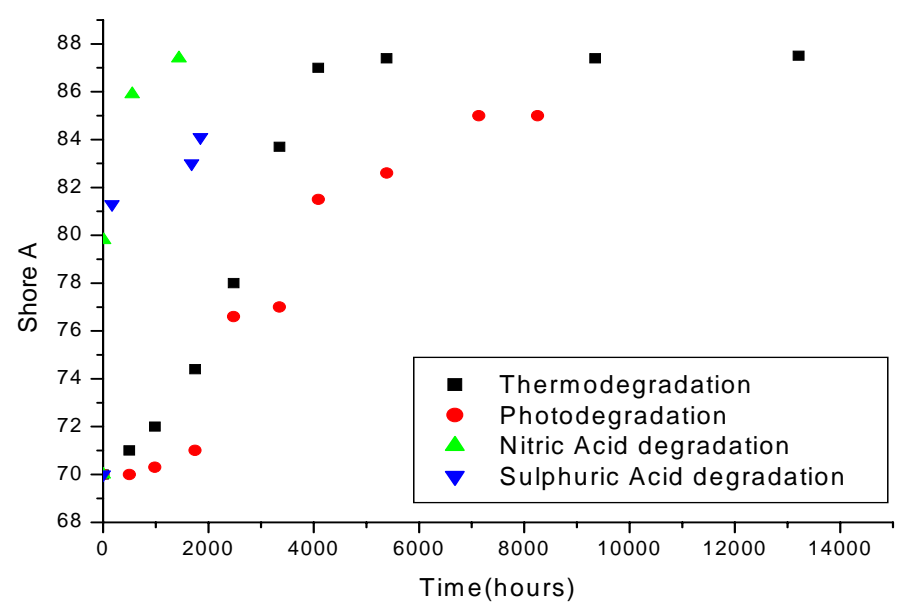

Fig. 4. Hardness measurements after different ageing. 


\section{DSC-thermoporosimetry results}

To estimate the cross-linking densities and to explain other structural changes upon degradation, DSC-thermoporosimetry measurements were carried out. This application of DSC has already been validated for dienic elastomers and silicone rubber [9]. The initial material (unaged sample) shows a distribution of mesh sizes with two peaks (figure 5). Different cuts $(180 \mu \mathrm{m}$ thick slices) from the surface of the rubber sheet have been characterized. We can underline that most meshes have a radius (distance between cross-links) around $200 \AA$, the other mesh size is around $700 \AA \AA$.

After photochemical or thermal ageings (Figure 6) we obtain different distributions. After short exposures ( $<1000$ hours, Figure 6A) we always get two peaks. The first one gives a radius around $200 \AA$, the second peak is shifted to $400 \AA$. This means that post cross-linking reactions are first detected. The cross-linking density is therefore affected by usual ageing. For longer time (1,000-5,000 hours) we can notice with figure $6 \mathrm{~B}$ that only one peak is observed at $550 \AA$ after thermal ageing. Chain scissions largely occured and gave such repetitive results. The same behaviour is confirmed after 10,000 hours.

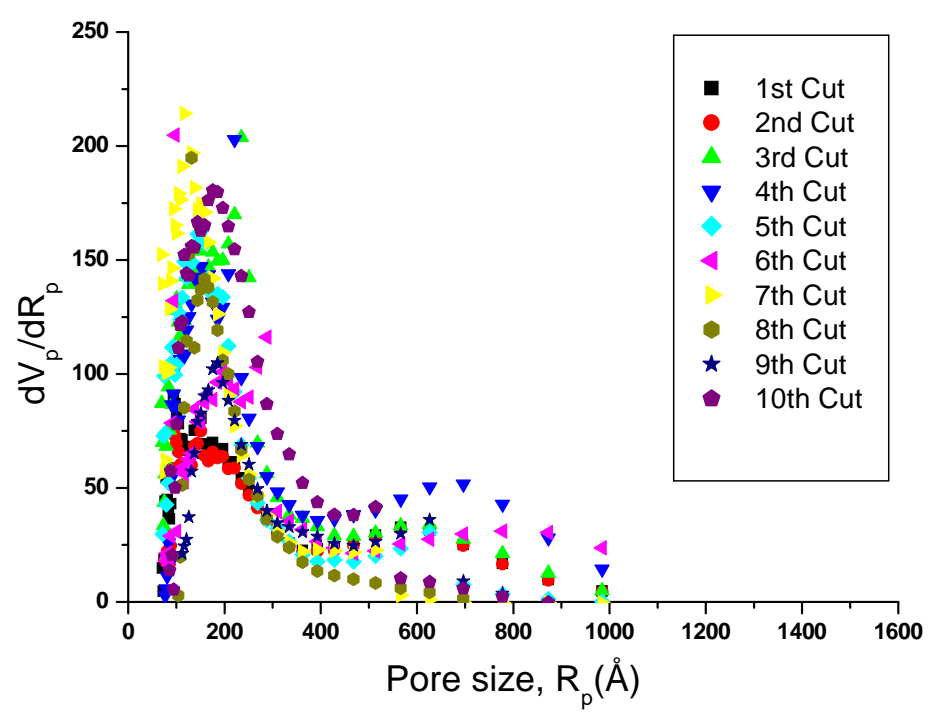

Fig. 5. Cross-linking profile obtained by DSC-thermoporosimetry on unaged sample surface (radius or pore size Rp, distribution $\mathrm{dV} / \mathrm{dR}$ ).

In the case of photo-ageing (Figure $6 \mathrm{C}$ ) we also get one peak around 1,200 $\AA$ after 2,000 hours. The photo-degradation process leads to a number of chain scissions. After 5,000 hours, new cross-linking reactions on the rubber surface can be detected (Figure 6D). The observed distribution curve gives one peak at $700 \AA$. With hardness measurements, we do not observe such differences between photochemical and thermal ageings. DSC-thermoporosimetry is a more sensitive technique.

After acidic treatment such as $\mathrm{HNO}_{3}$ the estimation of post cross-linking is done for short time of exposure (Figure 6E). It was not possible to do the measurements for very hard samples (aged more than 3 hours). The distribution is narrower and the average radius value is $900 \AA$. Chain scission reactions are the main path for material degradation, simultaneously with the decomposition of the fire retardant at the polymer surface. 


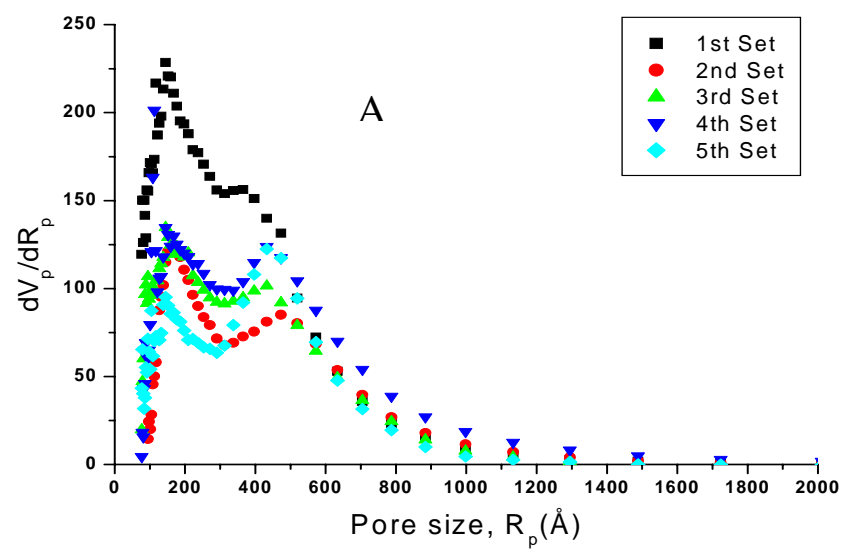

C
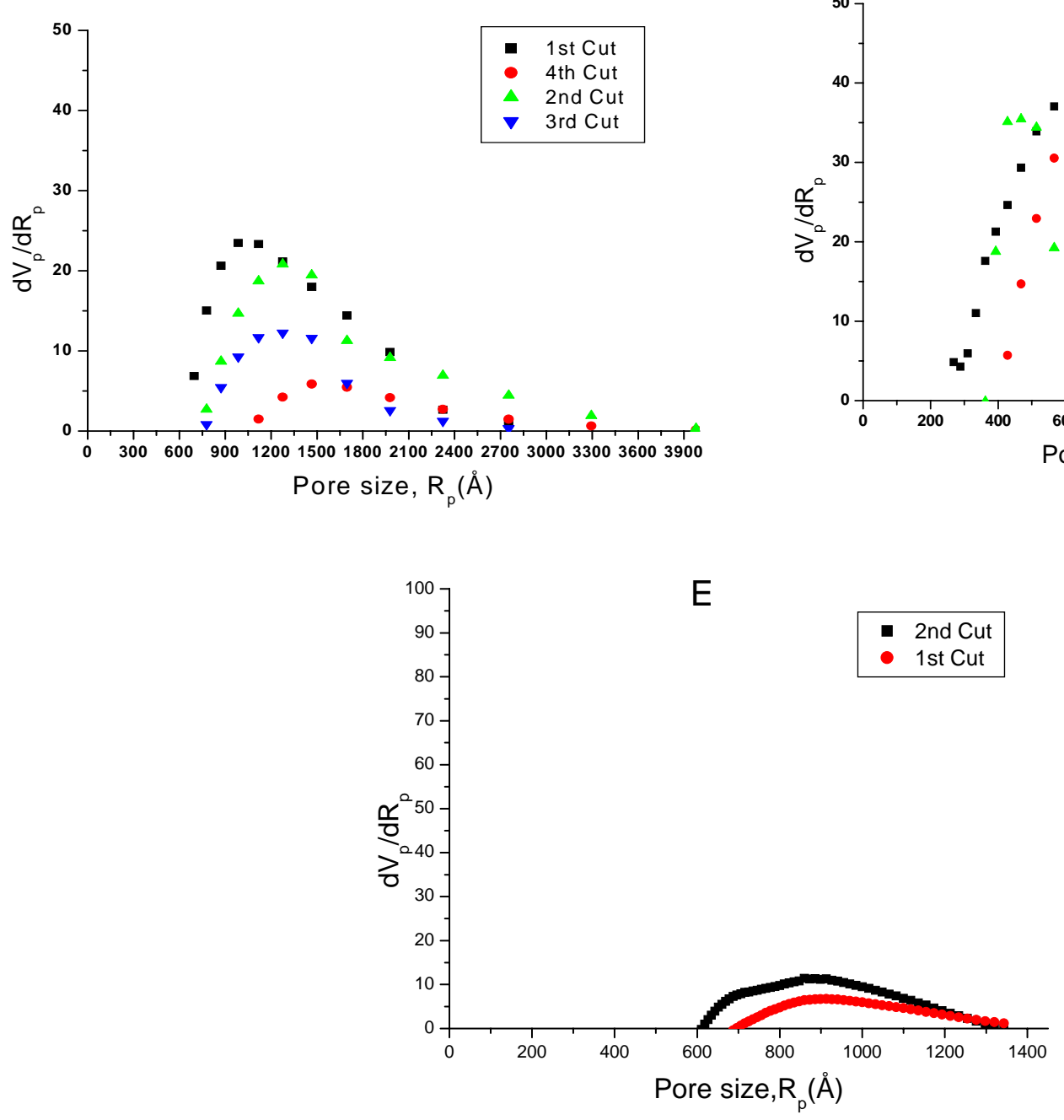
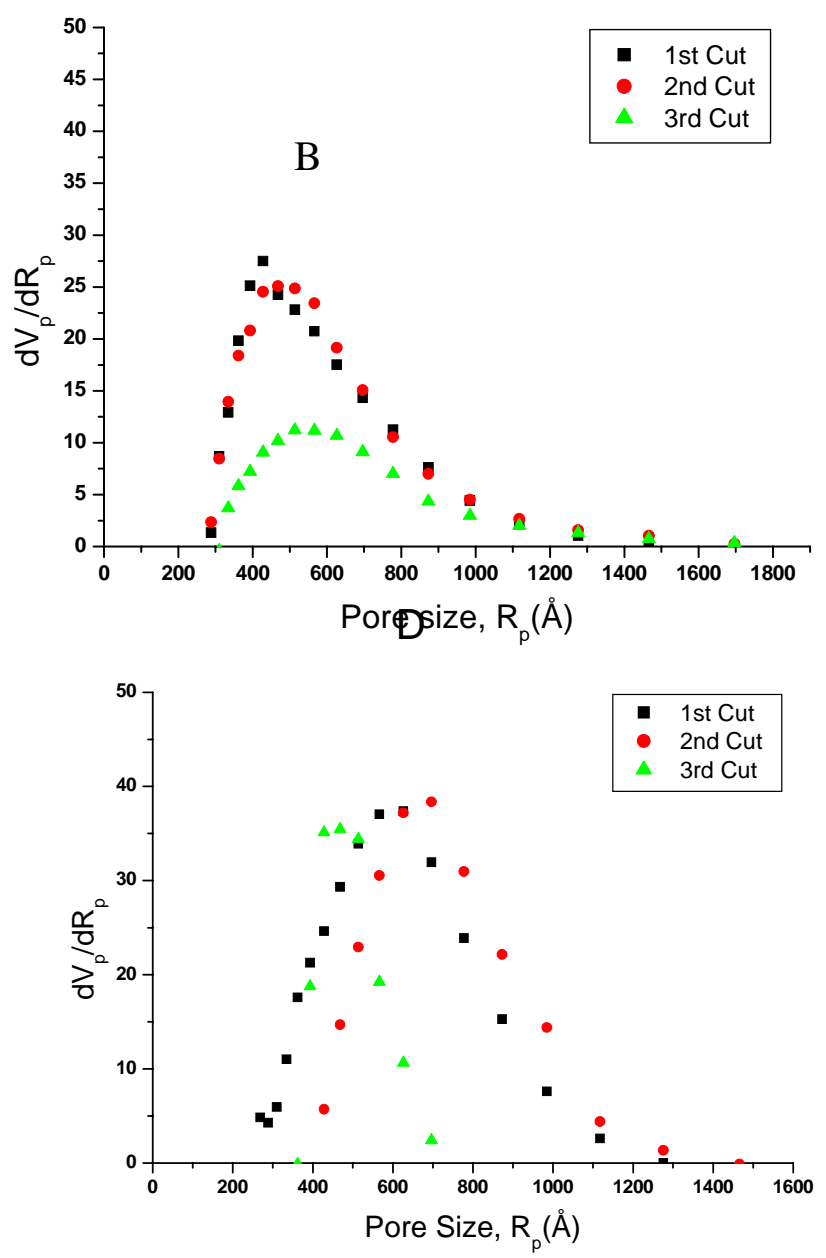

Pore Size, $R_{p}(\AA)$

Fig. 6. Cross-linking profile obtained by DSC-thermoporosimetry on aged sample surface; A- 907 hours in oven; B- 4000 hours in oven; C- 2000 hrs in photochemical device; D- 7000 hours in photochemical device; E- Nitric acid treatment 1 hour. 

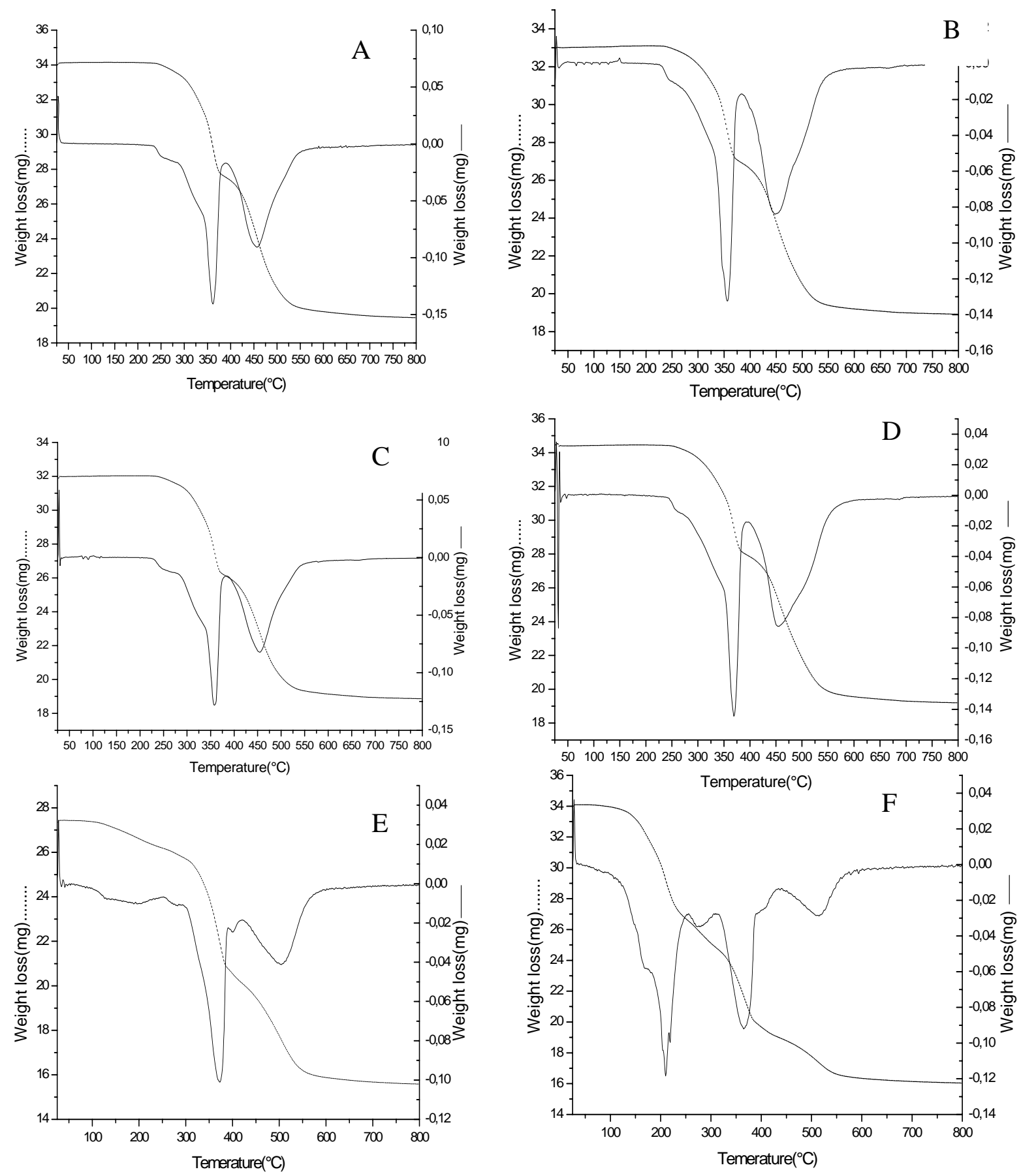

Fig. 7. TGA of silicone rubber before and after ageing (weight loss and derivate curves); A- Unaged sample; B-10 000 hours in photochemical device; C- 10000 hours in oven; D-260 hours under sulfuric acid treatment; E- 48 hours under nitric acid treatment; F- 2 months under nitric acid treatment. 

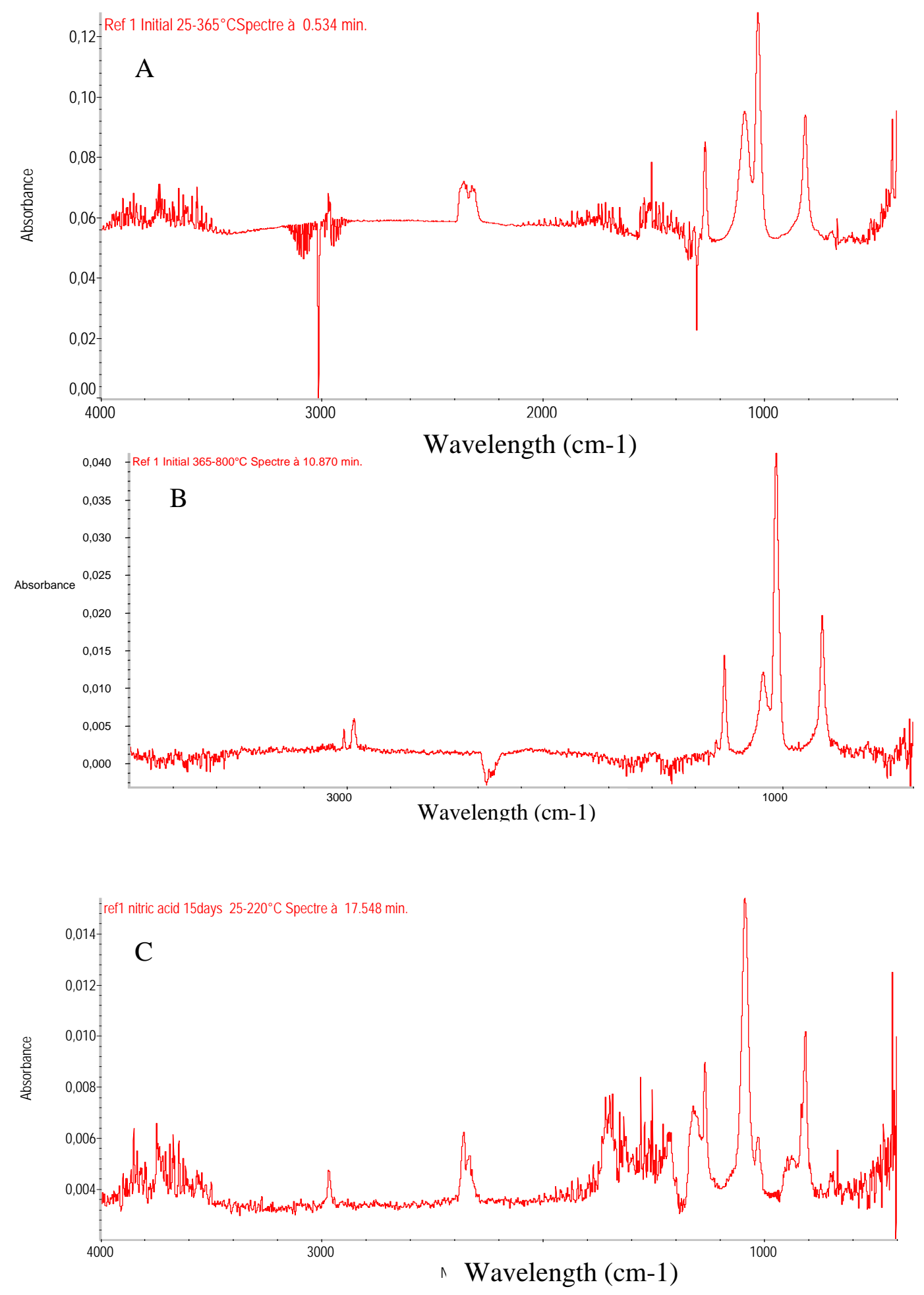

Fig. 8. FTIR results on gaz coming from TGA. A- First part $\left(360^{\circ} \mathrm{C}\right)$ for unaged sample; B- Second part $\left(450^{\circ} \mathrm{C}\right)$ for unaged material; $\mathrm{C}-\mathrm{New}$ bands for the sample under nitric acid treatment (15 days).

The TGA curves obtained after a thermal decomposition from $20^{\circ} \mathrm{C}$ to $800^{\circ} \mathrm{C}$ by $10^{\circ} \mathrm{C} / \mathrm{min}$ under oxygen allowed us to compare the thermal stability of silicone rubber after various ageing (figure 7). The curve 7A with the weight loss shows the 
decomposition of unaged filled cross-linked sample, which starts at $250^{\circ} \mathrm{C}$, due to $\mathrm{Al}(\mathrm{OH})_{3}$ deshydratation. We can mainly notice two peaks (derivative curve) with two stages of decomposition (end-set temperatures 360 and $450^{\circ} \mathrm{C}$ ). We get the same results after different times under photochemical, thermal ageing and exposure to sulphuric acid vapours (curves $B, C$ and $D$ ) It means that post cross-linking or chain scission occurred upon ageing and detected with other techniques, does not affect the thermal stability of silicone material. The first IR spectra of the gas coming from the degradation show main bands attributed to $\mathrm{H}_{2} \mathrm{O}$ and $\mathrm{CO}_{2}$. Then new bands of siloxane oligomers at 1260,1090,1030, and $790 \mathrm{~cm}^{-1}$ are detected (figures $8 \mathrm{~A}$ and B). The two peaks at $360^{\circ} \mathrm{C}$ and $450^{\circ} \mathrm{C}$ show the presence of several siloxane oligomers. The presence of $\mathrm{H}_{2} \mathrm{O}$ and $\mathrm{CO}_{2}$ decreases upon the degradation after $360^{\circ} \mathrm{C}$ is also noticed for the last part of decomposition. Its assignment was not successful. The thermal oxidative decomposition after nitric acid treatment is quite different and depends on the time of exposure. After 48 hours in $\mathrm{HNO}_{3}$ vapours the weight loss starts at $150^{\circ} \mathrm{C}$ (figure $7 \mathrm{E}$ ). This means that the thermal stability of the formulation is weaker compared to other ageing. The main peak on derivative curve gives an end-set temperature at $360^{\circ} \mathrm{C}$. We underline also the presence of a peak around $500^{\circ} \mathrm{C}$. After 7 days the weight loss for the first peak at $150-200^{\circ} \mathrm{C}$ increases (figure 7F). The second peak intensity at $360^{\circ} \mathrm{C}$ decreases. We can always observe the peak at $500^{\circ} \mathrm{C}$. The IR spectra allow detecting of the presence of $\mathrm{H}_{2} \mathrm{O}$ and $\mathrm{CO}_{2}$ and new siloxane oligomers bands (figure $8 \mathrm{C}$ ). A new band at $1380 \mathrm{~cm}^{-1}$ of strong intensity is also noticed for the last part of decomposition. Its assignment was not successful.

\section{Conclusion}

This work confirms the stability towards oxidation upon accelerated ageings of filled cross-linked silicone rubber. Changes in the IR spectra could not be detected even after 10000 hours in UV device or oven. The presence of aluminium trihydate in the formulation is clearly identified to be a problem in terms of long term behaviour after nitric acid treatment. Post cross-linking and chain scission reactions are revealed by hardness mesurements and DSC-thermoporosimetry after usual ageings (photochemical, thermal) and exposures to acidic vapours. The main path of degradation (chain scission or cross-linking) depends on the ageing. To avoid this degradation process stabilizers should be tested in such formulation. TGA-FTIR results allow us to compare the thermal stability of silicone rubber after various ageings. The thermal decomposition of samples after nitric acid treatment is quite different from the degradation obtained for unaged material or other aged rubbers.

The studied formulation gives satisfactory results towards usual ageings (an induction period is identified). In the case of polluted ageing (with $\mathrm{HNO}_{3}$ ) we need to do some improvements by adding specific stabilizer or removing the actual fire retardant. In this paper we have also tried to highlight the choice of techniques and the complementary nature of each.

\section{Experimental part}

\section{Materials}

Silicone rubber (HTV - High Temperature Vulcanized) is polydimethylsiloxane kindly provided by SEDIVER, France. The composition of the filled cross-linked PDMS is 
given in Table 2. The presence of silica can be noticed. The curing agent is 2, 5 dimethyl 2,5 di(t-butylperoxy) hexane (DHBP).

$$
\left(\mathrm{CH}_{3}\right)_{3} \mathrm{C}-\mathrm{O}-\mathrm{O}-\mathrm{C}\left(\mathrm{CH}_{3}\right)_{2}-\mathrm{CH}_{2}-\mathrm{CH}_{2}-\left(\mathrm{CH}_{3}\right)_{2} \mathrm{C}-\mathrm{O}-\mathrm{O}-\mathrm{C}\left(\mathrm{CH}_{3}\right)_{3}
$$

The formulation contains a flame retardant which is aluminium trihydrate. Thick $2 \mathrm{~mm}$ sheets were prepared for the ageing and the characterization. The curing time by compression moulding at $170^{\circ} \mathrm{C}$ was 12 minutes; this time corresponds to the usual optimal curing conditions. Sulphuric acid (95\%), nitric acid (68\%) and sodium chloride were products coming from Prolabo (VWR). We also used a crude hydroxy terminated PDMS coming from Scientific Polymer Products $\left(\mathrm{Sp}^{2}\right)$. This sample is reference 870 with a molecular weight of $90,000 \mathrm{~g} / \mathrm{mol}$ (GPC).

Tab. 2. Composition of filled cross-linked PDMS

\begin{tabular}{|l|l|}
\hline Composition & Quantity \\
\hline PDMS & 100 parts \\
\hline Silica & 23 parts \\
\hline Alumina Trihydrate & 80 parts \\
\hline DHBP & 0.4 part \\
\hline
\end{tabular}

\section{Ageing}

Five types of ageing were tested for comparison. An accelerated classical photoageing was performed directly on the silicone rubber sheets. The irradiation device (SEPAP 12-24) has been described previously [23]. The system is characterised by the source, medium pressure $\mathrm{Hg}$ lamps filtered with borosilicate envelope $(\lambda>300 \mathrm{~nm})$ and by careful control of the temperature with a thermocouple in close contact with one of the samples. Samples are rotated at a constant distance $(20 \mathrm{~cm})$ from the sources. The samples were irradiated at $60^{\circ} \mathrm{C}$ in a SEPAP chamber equipped with four lamps.

We used an aerated oven (MEMMERT) for thermal exposure at $100^{\circ} \mathrm{C}$. The other ageing was salt-fog test usually used for metallic materials $(\mathrm{H}$. KOHLER - HK 320). The conditions of this test were the concentration of $\mathrm{NaCl}(5 \%$ weight) and the temperature at $35^{\circ} \mathrm{C}$. We finally used dessicators to carry out polluted ageings, such as nitric acid vapours or sulphuric acid vapours at room temperature.

\section{Analytical tools}

The chemical changes upon irradiation were followed by FTIR-ATR spectroscopy (Attenuated Total Reflectance - Nicolet Impact 400 and Thunderdome accessory with germanium crystal). With this reflection analysis we can operate on thick sheets (for example cross-linked and coloured polymers). We analyse the material surface upto a few micrometers.

Hardness measurements were done with a Zwick Werk (NR 83195) - Shore A (weight $1 \mathrm{~kg}$ ) system on polymer sheets before and after ageings. Ten measurements were made and an average value was then given.

The evolution of cross-linking is followed by DSC-thermoporosimetry. It is a calorimetrical technique used for the visualization of the material texture by studying the phase transition (crystallization, melting or other change of state) undergone by 
the swelling solvent (cyclohexane) trapped in the polymeric network. The transition temperature of this confined solvent depends on the characterisation of the surrounding polymeric swollen network. The thermoporosimetry has essentially been applied to rigid porous substrates [24, 25]. The theoretical basis was established by Brun et al. [24]. It is assumed that a polymeric gel is equivalent to a three dimensional network of adjacent cells that is called mesh. The solvent swells the crosslinked polymer until equilibrium state is reached. It yields to a swollen gel where the solvent is present under two environments : the confined solvent which is trapped inside the gel and the part of solvent which remains out and represents the excess (free solvent). The free solvent behaves like a pure solvent in term of phase transitions. On the other hand the confined solvent undergoes the phase transitions at different temperatures depending on the characteristics of surrounding polymeric network and especially depending on the size of the network mesh. The difference in the transition temperature $\Delta \mathrm{T}$ between free and confined solvent can be related to the size of the mesh for elastomers. Differential Scanning Calorimetry can be used to measure $\Delta T$ precisely. Calibrations have been done for obtaining useful thermodynamical data from the solid to solid cyclohexane transition [26]. The following empirical relationships have been established :

$$
\begin{gathered}
R(A)=16.93+125.43 * \exp \left(-\frac{1 / \Delta T+0.0756}{0.0205}\right) \text { with }-55 \leq \Delta T \leq 0^{\circ} \mathrm{C} \text { for cyclohexane } \\
\frac{d V}{d R}=K \frac{y^{*}(\Delta T)^{2}}{W a^{*} \exp \left(-\frac{1 / \Delta T+0.0756}{0.0205}\right)} \text { (2) }
\end{gathered}
$$

$$
W a(J / g)=0.0203 *(\Delta T)^{2}+2.6034 * \Delta T+82.199 \text { with } 0>\Delta T>-55^{\circ} \mathrm{C}
$$

where $R(\AA)$ is the distance between cross-links in the swollen gel, expressed in Angstrom and $\Delta T=T-T_{0}$, the temperature depression of the swelling solvent determined from the thermal DCS curve with $T_{0}=-88.63^{\circ} \mathrm{C}$ for cyclohexane, $\mathrm{V}$ is the volume of the solvent concerned by the thermal transition and contained in network cells, $\mathrm{R}$ is the distance between cross-links, $K$ is a proportionality coefficient that depends on both the DSC instrument and the swelling solvent, $y$ is the DSC thermal curve ordinate and $W a$ the apparent energy of the solid-solid transition. DSC instrument is a METTLER TOLEDO DSC 30 used from $-88^{\circ} \mathrm{C}$ to $-106^{\circ} \mathrm{C}$ at $0.7^{\circ} \mathrm{C} / \mathrm{min}$ to see the crystalline solid-solid transition. A cryogenic microtome LEICA Jung Supercut LN20 was used at $-50^{\circ} \mathrm{C}$ to cut the $2 \mathrm{~mm}$ sheets into small slices of $180 \mu \mathrm{m}$ thick.

Other results were obtained with a coupled equipment TGA-FTIR (METTLER TOLEDO TGA/SDTA851 - NICOLET Nexus). Gas coming from TGA is transfered with a heating tube in a gas cell and characterized by FTIR. The temperature method was a dynamic segment from 20 to $800^{\circ} \mathrm{C}$ by $10^{\circ} \mathrm{C} /$ minute under oxygen $(40 \mathrm{ml} / \mathrm{min})$. The IR experiments were done every minute during the entire thermogravimetric program. 


\section{Acknowledgements}

This work has been supported by the Indo-French Centre for the Promotion of Advanced Research (IFCPAR) through project 7104. Thanks to E. Brocard and G. Thevenet from SEDIVER, France for their advices.

\section{References}

[1] Israëli Y,Philippart JL, Cavezzan J, Lacoste J and Lemaire J.; Polym. Degrad. Stab. 1992, 36,179-185.

[2] Israëli Y, Cavezzan J and Lacoste J.; Polym. Degrad. Stab. 1992, 37, 201-208. [3] Israëli Y, Lacoste J, Cavezzan J and Lemaire J.; Polym Degrad Stab 1993, 42, 267-279.

[4] Israeli Y, Lacoste J, Cavezzan J and Lemaire J.; Polym Degrad Stab 1995; 47: 357-362.

[5] Grassie N, Francey KF, Macfarlane IG.; Polym Degrad Stab 1980, 2, 67-83.

[6] Camino G, Lomakin SM, Lazzari M.; Polymer 2001, 42, 2395-2402.

[7] Camino G, Lomakin SM, Lazzari M.; Polymer 2002, 43, 2011-2015.

[8] Virlogeux F, Bianchini D, Delor-Jestin F, Baba M and Lacoste J.; Polymer International 2004, 53,163-168.

[9] Zeldin M, Qian BR and Choi SJ.; J. Polym. Sci. - Polym. Chem. Ed. 1983, 21, 1361-1369.

[10] Hillborg H, Sandeli M, Gedde UW.; Polymer 2001; 42, 7349-7362.

[11] Hillborg H and Gedde UW.; IEEE Transactions on Dielectrics and Electr Insulation; Oct 19996 (5), 703-717.

[12] Smith PJ, Owen MJ, Holm PH and Toskey GA.; IEEE CEIDP 1992; Annual report - Surface studies of corona-treated silicone.

[13] Owen MJ, Gentle TM, Orbeck T and Williams DE. Dynamic wettability of hydrophobic polymers, Polymer Surface Dynamics, Ed JD Andrade - Plenum Press 1988.

[14] Vlastos AE and Gubanski SM.; IEEE Transactions on Power Delivery April 1991, 6(2), 888-900.

[15] Sorqvist T and Vlastos AE.; IEEE Transactions on Power Delivery April 1997, 12(2), 1041-1047.

[16] Kim SH, Cherney EA, Hackam R and Rutherford KG.; IEEE Transactions on Dielectrics and Electrical Insulation Feb 1994, 1(1), 106-123.

[17] Hackam R.; IEEE Transactions on Power Delivery; October 1999, 6(5), 557-585. [18] Homma H, Mirley CL, Ronzello J and Boggs SA.; IEEE Transactions on Power Delivery October 2000, 15(4), 1298-1303.

[19] Fateh-Alavi K., Gallstedt M., Gedde UW.; Polym. Degrad. Stab. 2001, 74: 49-57. [20] Chaudhry AN, Billingham NC.; Polym. Degrad. Stab. 2001, 73, 505-510.

[21] Patel M and Skinner AR.; Polym. Degrad. Stab. 2001, 73, 399-402.

[22] Zhang J, Feng S and Ma Q.; J. Applied Polym. Science 2003, 89, 1548-1554.

[23] Penot G, Arnaud R, Lemaire J.; Die Angew. Makromol. Chem.1992, 30, 493499.

[24] Quinson JF, Astier M and Brun M.; Applied catalysis 1987, 30, 123-127.

[25] Liu J, Gan LM, Chew CH and Teo WK.; Langmuir 1997, 13, 6421-6425.

[26] Baba M., Nedellec JM., Gardette JL., Lacoste J.; Journal of non-crystalline solids Jan 2003, 31(3), 228-238.

[27] Socrates G.; IR and Raman characteristics group frequencies $3^{\text {rd }}$ Edition Wiley 2001, 244. 